\title{
Statistischer Bericht
}

über die

in der Policlinik zu Halle a/S. im Winter-Semester 1867/68 bis Sommersemester 1869 inclusive untersuchten und behandelten Ohrenkranken

ron

\section{Prof. Schwartze.}

In dem Zeitraum rom 15. October 1867 bis 15. October 1869 sind im Ganzen 450 Ohrenkranke zur Untersuchung resp. Behandlung der Policlinik gekommen, nämlich 7 Restanten vem Sommersemester 1867 und 443 neue Patienten. Von diesen wurden in Behandlung genommen 402 ; die übrigen 41 wurden nur ein- oder mebrmals untersucht, ohne dass eine Behandlung eingeleitet wurde.

Das allgemeine Resultat der Behandlung war Folgendes :

Gebeilt wurden . . . . . 225

Wesentlich gebessert . . . . 82

Ungeheilt entlassen $\quad \cdot \quad \cdot \quad \cdot \quad \cdot \quad 23$

Ohne Behandlung entlassen . . . 43

Erfolg der Behandlung blieb unbekannt,

weil die Patienten ausblieben, bei . 63

In Behandlung verblieben . . . 11

Gestorben . . . $\frac{3}{\text { Summe }}$

Ueber die Erkrankungsformen und deren Ausgang gibt die folgende Tabelle Auskunft: 
Verseiohniss der Erkrankungen und deren Ausgang.

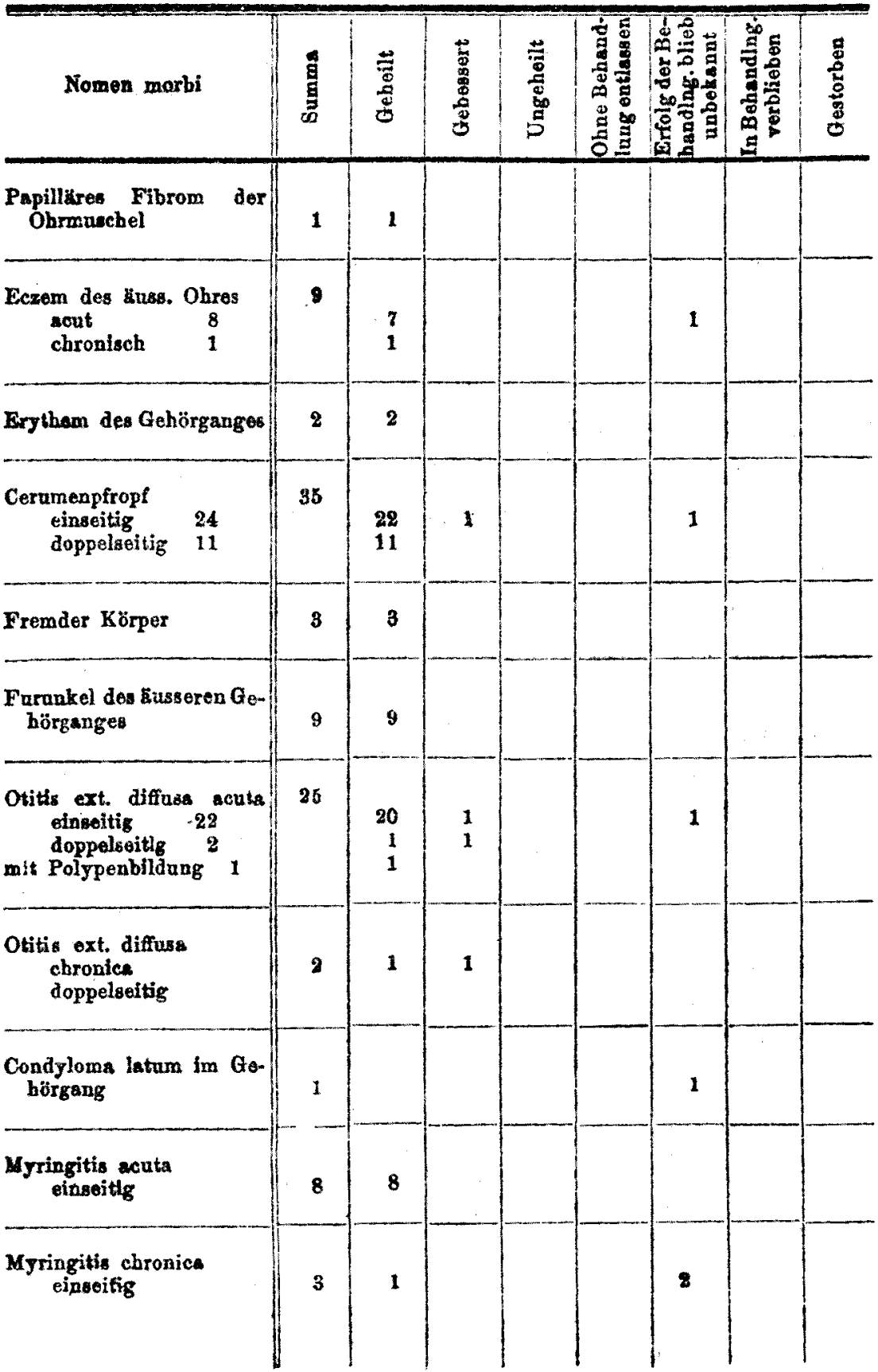




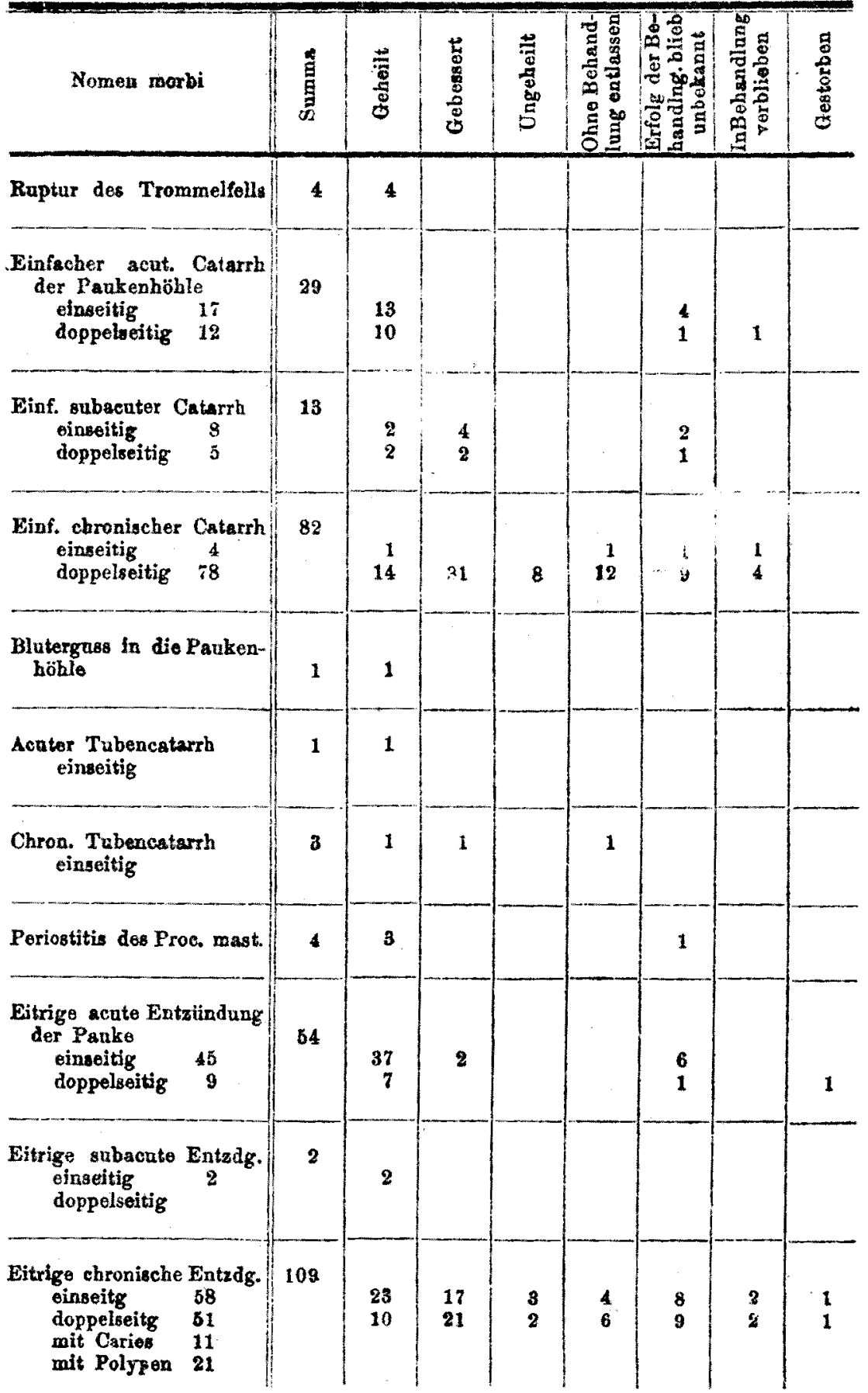




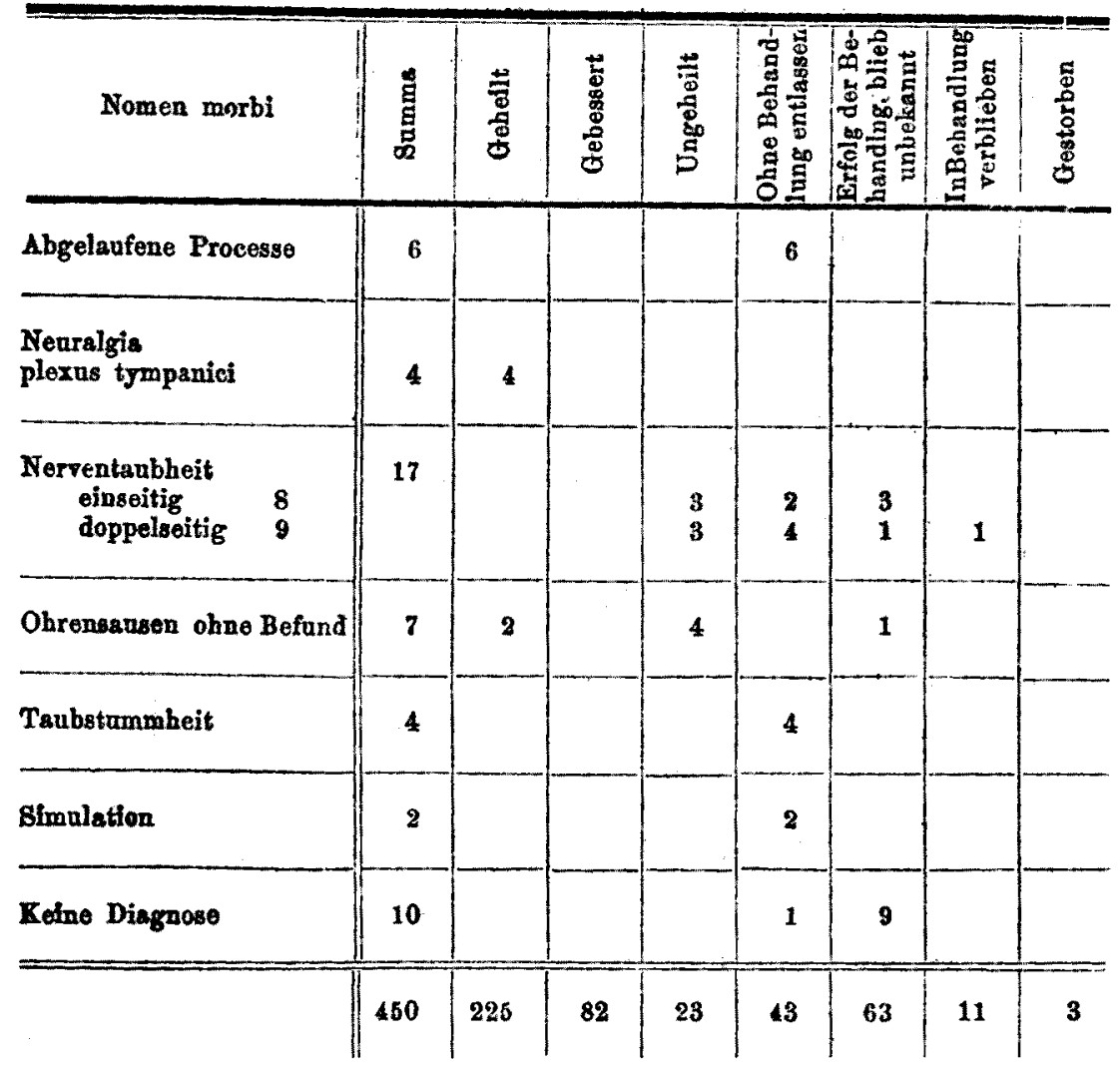

Bei der Behandlung der Kranken wurde ich in den verflossenen 2 Jahren besonders unterstützt durch die Herren Dr. Dr. Küpper und Bertuch. Der erstere leistete auch bei der Anfertigung dieses statistischen Berichtes, der abweichend von den früheren diesmal 2 Jahre umfasst, aufopfernde Hullfe.

Durch die wohlwollende Fürsorge des Direetors der medicinischen Klinik Herrn Prof. Theod. Weber war es auch in den verflossenen Jahren möglich, dem überwiegend grössten Theil der Patienten neben der von uns gewahrten freien Behandlung auch freie Arznei zu verabfolgen. 